\title{
Intravenous Nicotine Self-Administration in Smokers: Dose-Response Function and Sex Differences
}

\author{
Kevin P Jensen', Elise E DeVito', Gerald Valentine', Ralitza Gueorguieva ${ }^{2}$ and Mehmet Sofuoglu*,I \\ 'Department of Psychiatry, School of Medicine, Yale University, VA Connecticut Healthcare System, West Haven, CT, USA; ${ }^{2}$ Department of \\ Biostatistics, Yale University School of Public Health and School of Medicine, New Haven, CT, USA
}

\begin{abstract}
Sex differences in the sensitivity to nicotine may influence vulnerability to tobacco dependence. The goal of this study was to investigate the dose-response function for the reinforcing and subjective effects of intravenous nicotine in male and female smokers. Tobacco-dependent subjects ( 12 male and 14 female) participated in four experimental sessions in which they received sample infusions of saline and nicotine $(0.1,0.2,0.3$, or $0.4 \mathrm{mg}$ doses $)$ in a randomized double-blind crossover design. During each session, subjects first received the sample infusions, and heart rate $(H R)$, blood pressure, and subjective stimulatory, pleasurable and aversive responses were monitored. Immediately following the sample infusions, subjects self-administered either nicotine or saline in six double-blind forced-choice trials. A sex by dose interaction was observed in the nicotine choice paradigm. Nicotine self-administration rate was negatively correlated with nicotine dose in males (males displayed choice preference for low doses of nicotine over high doses of nicotine), but no significant relationship between dose and choice preference was evident in females. Relative to placebo, sample doses of nicotine increased heart rate and blood pressure, and induced stimulatory, pleasurable, and aversive subjective effects. Diastolic blood pressure increased dose dependently in males, but not in females. These findings, which demonstrate sex differences in nicotine self-administration for doses that are near to the reinforcement threshold, suggest that male and female smokers may respond differently to the changes in nicotine doses available for self-administration. Neuropsychopharmacology (2016) 4I, 2034-2040; doi: I 0.1038/npp.20I5.373; published online 3 February 2016
\end{abstract}

\section{INTRODUCTION}

With the legislation that empowered the Food and Drug Administration to control tobacco products, reducing the addiction potential and harmful effects of cigarette smoking became a more achievable goal. Benowitz and Henningfield (1994) proposed that the gradual reduction of the nicotine content of cigarettes to an amount below the addictive threshold could prevent the development of addiction among young smokers who are experimenting with cigarettes (Benowitz and Henningfield, 1994). On the basis of the nicotine intake of a group of smokers known as chippers or light and intermittent smokers, who show few or no signs of addiction, Benowitz and Henningfield (1994) estimated that the threshold for nicotine reinforcement is $\sim 0.2 \mathrm{mg}$ of delivered nicotine. They further predicted that nicotine doses below this threshold would not be reinforcing or able to maintain nicotine addiction. The dose-response function for nicotine reinforcement, however, has yet to be empirically examined by carefully controlled studies in humans.

Intravenous (IV) self-administration models are the gold standard for assessing the reinforcing effects of drugs of

* Correspondence: Dr M Sofuoglu, Department of Psychiatry, School of Medicine, Yale University, VA Connecticut Healthcare System, 950 Campbell Ave., Bldg. 36/I I 6A4, West Haven, CT 065 I6, USA, Tel: 203 937 4809, Fax: 203937 3478, E-mail: Mehmet.Sofuoglu@yale.edu Received 16 November 20 I5; revised 3 December 2015; accepted 5 December 2015; accepted article preview online 31 December 2015 abuse, including nicotine. Henningfield and colleagues pioneered IV nicotine self-administration (NSA) procedures in humans (Harvey et al, 2004; Henningfield and Goldberg, 1983a; Henningfield et al, 1983b). When nicotine is infused rapidly (ie, in $<60 \mathrm{~s}$ ) it produces robust 'drug liking' and 'good drug effects' (indicative of reward) that are similar to cigarette smoking. The nicotine doses used in these prior studies exceed the nicotine concentrations typically experienced by a smoker, which is $1-4 \mathrm{mg}$ nicotine per hour (Benowitz and Jacob, 1990). In a previous study of male and female smokers, we examined self-administration of IV nicotine using a choice procedure in which smokers were able to choose between three IV nicotine doses and saline. In that study, we used single nicotine doses $(0.1,0.4$, and $0.7 \mathrm{mg}$ ) that were in the range of intake experienced by smokers taking one to several puffs of a cigarette (Sofuoglu et al, 2008). We found that both 0.4 and $0.7 \mathrm{mg}$ doses were preferred over placebo. However, many questions remain for NSA in humans, including the generation of a reliable estimate for the threshold dose for reinforcement, as well as a dose-response curve for reinforcement. In animal models (Corrigall et al, 2000; Donny et al, 2000; Fattore et al, 2002; Le Foll et al, 2007; Rose and Corrigall, 1997), the dosedependent changes in nicotine reinforcement are restricted to low- and high-dose ends of the dose-response curve, whereas the middle range is relatively insensitive to changes in nicotine doses (Rose and Corrigall, 1997). It is unknown whether a similar NSA pattern exists in humans as well. 
Table I Sample Demographics and Tobacco Smoking Information

\begin{tabular}{|c|c|c|c|c|}
\hline & \multicolumn{2}{|c|}{ Male $(n=12)^{*}$} & \multicolumn{2}{|c|}{ Female $(n=14)$} \\
\hline & Mean & SD & Mean & SD \\
\hline Age & 36.7 & 6.8 & 37.6 & 9.2 \\
\hline Weight & 199.2 & 30.4 & 194.4 & 56.8 \\
\hline FTND & 5.3 & 2.3 & 5.9 & 1.9 \\
\hline BMI & 28.5 & 3.5 & 33.1 & 9.2 \\
\hline Cigarettes smoked per day & 21.4 & 10.5 & 16.9 & 10.9 \\
\hline Age of smoking onset & 15.8 & 3.5 & 15.4 & 2.0 \\
\hline Estimated pack years & 22.9 & 13.1 & 18.4 & 11.4 \\
\hline Ancestry & \multicolumn{2}{|c|}{$\mathbf{N}$} & \multicolumn{2}{|c|}{$\mathbf{N}$} \\
\hline European American & \multicolumn{2}{|c|}{7} & \multicolumn{2}{|c|}{5} \\
\hline African American & \multicolumn{2}{|c|}{5} & \multicolumn{2}{|c|}{9} \\
\hline
\end{tabular}

Abbreviations: BMI, body mass index; FTND, Fagerstrom test for nicotine dependence score.

*P $>0.05$ for all male vs female comparisons

The purpose of this study was to characterize the doseresponse curve for IV NSA in male and female smokers, which has not been examined in previous human studies. To reach this goal, we used a NSA model that included nicotine doses of $0.1,0.2,0.3$, and $0.4 \mathrm{mg}$, which approximates the nicotine intake from inhaling one to four puffs of a cigarette. We hypothesized that this range of nicotine doses would be near the threshold dose for reinforcement. In addition to self-administration, we also collected measures of heart rate (HR), blood pressure, and positive and negative subjective ratings of drug effects. Given the preclinical and clinical studies that indicate there are sex differences in nicotine's pharmacological effects (Pogun and Yararbas, 2009), inclusion of both male $(n=12)$ and female $(n=14)$ smokers allowed us to examine sex differences in the reinforcing threshold of IV nicotine.

\section{MATERIALS AND METHODS}

\section{Subjects}

The subjects were non-treatment seeking, dependent smokers recruited from the New Haven, CT area. Demographic variables and cigarette smoking history for males and females are shown in Table 1 . Twelve male and 14 female subjects participated in all four sessions; 6 subjects were removed from all analyses because they were not compliant with study procedures or they opted out voluntarily before study completion. There were no sex differences in demographics or smoking history $(P>0.05)$. All participants had normal physical, laboratory, and psychiatric examinations, and participants had no current drug abuse or dependence for any substances other than nicotine, as established by the structured clinical interview for DSM-IV (American Psychological Association, 1994). A urine drug screening before each session was performed to assess for recent exclusionary drug use (opiates, phencyclidine, cocaine, amphetamines, and benzodiazepines). Each participant gave a signed informed consent before the study participation. All the sessions were conducted in the Biostudies Unit located at the VA Connecticut Healthcare System (West Haven, CT) and the participants were paid for participation. This study was approved by Yale University and the VA Connecticut Healthcare System Human Subjects Subcommittee.

\section{Laboratory Study Procedures}

This outpatient, double-blind, crossover study had four experimental sessions. All experimental sessions were conducted following overnight smoking abstinence that was verified by measuring breath carbon monoxide levels $(<10$ parts per million; BreathCO, Vitalograph, Lenexa, KS). At the start of each session, an indwelling IV catheter was inserted in the subject's antecubital vein for nicotine infusion, blood drawing, and as a safety precaution. Each experimental session consisted of one randomly assigned nicotine dose $(0.1,0.2,0.3$, or $0.4 \mathrm{mg})$, as well as saline serving as placebo. At the start of each session, subjects first sampled their assigned nicotine dose (either $0.1,0.2,0.3$, or $0.4 \mathrm{mg}$ ) and placebo (saline) in random order. The nicotine dose and saline were randomly labeled as 'A' and 'B' by the pharmacist to maintain the study blind. Sample dose ' $B$ ' was administered $15 \mathrm{~min}$ after sample dose 'A'. Fifteen minutes after sample dose ' $\mathrm{B}$ ', subjects were given opportunities to choose whether they wished to receive either an infusion of ' $A$ ' or an infusion of 'B'. There were six 'A' $v s$ 'B' choice trials, each separated by $15 \mathrm{~min}$. Immediately following the subject's selection, ' $\mathrm{A}$ ' or ' $\mathrm{B}$ ' was administered over $30 \mathrm{~s}$ using an infusion pump activated by research staff. Cardiac rhythm was monitored continuously during sessions, and 12-lead ECGs were obtained before and at the end of the session. The sessions started at $\sim 0800$ hours and were spaced 2-7 days apart to minimize any carryover effects from nicotine.

\section{Nicotine and Placebo Preparation}

Nicotine stock solution vials were prepared by dissolving nicotine bitartrate dihydrate powder in $0.9 \%$ sodium chloride and passed through 0.22 -micron filters to target a $1 \mathrm{mg} / \mathrm{ml}$ concentration. The amount of nicotine bitartrate dihydrate powder was adjusted by molecular weight to reflect nicotine free base. Each batch of nicotine solution was tested for pyrogenicity, sterility, and analyzed by quantitative assay, which yielded satisfactory results in all cases. An investigational new drug application was obtained from the Food and Drug Administration for IV nicotine. Two $60 \mathrm{ml}$ syringes, marked as either ' $A$ ' or ' $B$ ', were prepared in randomized, double-blinded fashion with identical-looking IV labels and equal volumes $(46 \mathrm{ml})$. The syringe that contained the nicotine dose had enough volume to account for the line flush and seven experimental infusions, one for the sample dose and the six optional doses for the choice trials. The placebo syringe contained $46 \mathrm{ml}$ of $0.9 \%$ sodium chloride. Syringes were capped, labeled as 'A' or ' $\mathrm{B}$ ', and dispensed to the study staff by the research pharmacy.

\section{Outcome Measures}

Systolic and diastolic blood pressure (SBP and DBP), and HR were taken just before each sample dose infusion $(0 \mathrm{~min})$ and 


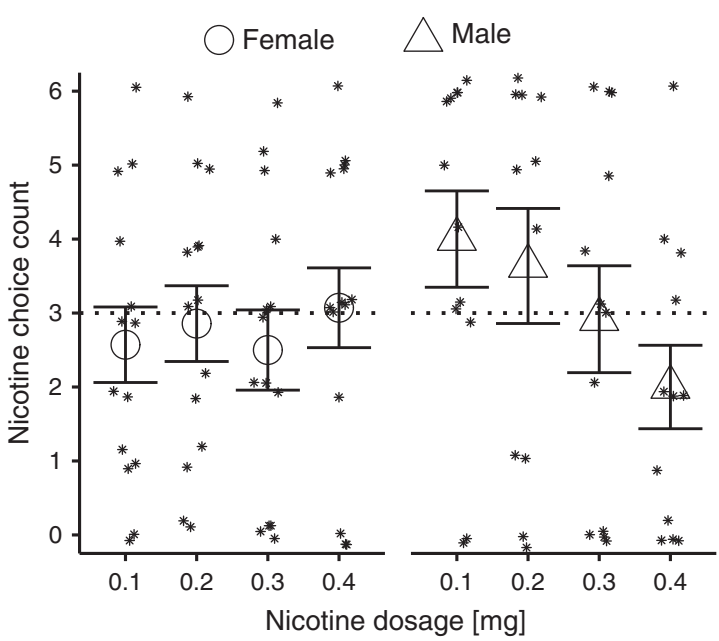

Figure I Sex differences in intravenous (IV) nicotine self-administration. Nicotine self-administration frequency was negatively correlated with nicotine dose among males but not females (dose by sex $P<0.05$ ). In males, 0.1 and $0.2 \mathrm{mg}$ nicotine was self-administered $>0.4 \mathrm{mg}$ nicotine $(P<0.05)$. The nicotine infusion number (maximum 6$)$ for male $(n=12)$ and female $(n=14)$ subjects and mean $( \pm$ SEM) value at each dose is shown.

then 1, 2, 3, 5, 8, and 10 min post infusion. The Drug Effects Questionnaire (DEQ) consisted of nine items that were grouped into three domains: (1) 'stimulatory' effects comprising the average of 'feel stimulated', 'feel effects', and 'feel high'; (2) 'feel good' effects comprising the average of 'like', 'feel good', and 'want more'; and (3) 'negative' effects comprising the average of 'feel anxious', 'feel down', and 'feel bad'. Each response was rated on a $100 \mathrm{~mm}$ scale, from 0 'not at all' to 100 'extremely', which was then converted to a rating from 1 to 10 . The nine items were grouped into three domains based on prior work showing high correlations between DEQ responses (Jensen et al, 2015a, b; Morean et al, 2013). The DEQ was given before each sample dose infusion $(0 \mathrm{~min})$ and then $1,3,5,8$, and $10 \mathrm{~min}$ post infusion. The DEQ was adapted from VAS questionnaires used in previous IV nicotine studies (Soria et al, 1996).

\section{Data Analysis}

Forced-choice preference and dose discrimination were evaluated using Generalized Estimating Equations (Zeger et al, 1988), with a negative binomial distribution for the number of times a participant chose nicotine in a session, and a log link and exchangeable working correlation structure across sessions within individuals. We tested the effects of sex, nicotine dose, and sex by nicotine dose, and controlled for consecutive session and drug administration order. One subject (male) failed to complete the sixth forcedchoice trial of the $0.2 \mathrm{mg}$ nicotine condition due to an infusion pump malfunction and this data point was regarded as missing. This subject had selected nicotine for five of five forced-choice trials, and including the data with either a selection of nicotine or saline for the final forced-choice trial yielded no material change to the results. Effects that were $<0.05$ significance level were interpreted with post hoc tests.

The main and interactive effects of sex were tested in all models for cardiovascular effects and subjective effects.
Cardiovascular effects were assessed using linear mixed effects models with SBP, DBP, and HR considered separately as response variables, sex as a between-subject factor, nicotine dose, drug (nicotine vs placebo), and time (all repeated measurements within each treatment on each test day) as within-subject factors, and all possible interactions. Period and sequence effects were controlled for by including test day and order of drug administration on each test day (nicotine first or placebo first) as additional predictors in the models. Two-way interactions between test day and order, and between drug and order were considered, but dropped from the models because they were not significant. Random effects for subject, test day within subject, and drug within test day and within subject were used to account for correlations between repeated measures. Post hoc tests were performed in order to explain significant interactions. Significance level of 0.05 was used for the tests of all interactions and main effects. Because of the skewed distributions of the subjective effects data, nonparametric analyses were performed. We used the nonparametric approach of Brunner et al (2002) for repeated measures data with stimulatory, pleasurable, and aversive effects considered separately as response variables. The raw subject effects data were converted into ranks first and then were entered into a mixed model with sex as a between-subject factor, nicotine dose, drug (nicotine vs placebo) and time (all repeated measures) as within-subject factors, and subject as the clustering factor. All interactions were tested in the model, and we controlled for period and sequence effects by including main effects and interactions of day and infusion order, and of infusion order and drug. Non-significant interactions involving day and infusion order were dropped from the final models. The variance-covariance structure was unconstrained. Contrasts were used to explain any significant interactions or main effects. The overall alpha level for each scale was fixed at 0.05. Post hoc tests were performed in order to explain significant interactions.

\section{RESULTS}

\section{Sex Differences in IV Nicotine Dose Preference and Discrimination}

There was a significant interaction between sex and nicotine dose $\left(\chi_{3}^{2}=9.51, P=0.02\right)$ for NSA. At the $0.1 \mathrm{mg}$ dose, but not at the other doses, males had more NSAs compared with females (estimated mean $M(\mathrm{SE})=3.97(0.66)$ for males $v s$ estimated $M(\mathrm{SE})=2.42(0.46)$ for females; $P=0.04)$. There was a significant negative linear relationship between selfadministration choices and nicotine dose among males $\left(\chi_{1}^{2}=9.10, P=0.003\right)$ but not among females $\left(\chi_{1}^{2}=0.99\right.$, $P=0.32$ ). Males chose to self-administer nicotine (over saline) more often at 0.1 and $0.2 \mathrm{mg}$ doses compared with the $0.4 \mathrm{mg}$ dose $(P=0.002$ and 0.007 , respectively). In contrast, among females there were no between-dose differences in choice preference for nicotine (over saline) across nicotine doses (Figure 1). The mean number of selfadministrations for nicotine or saline among female and among male subjects at each nicotine dose was not significantly different than three $(P>0.05)$, indicating no choice preference for nicotine or saline. At the first forcedchoice trial, 9 out of 12 males (75\%) chose the $0.1 \mathrm{mg}$ nicotine 

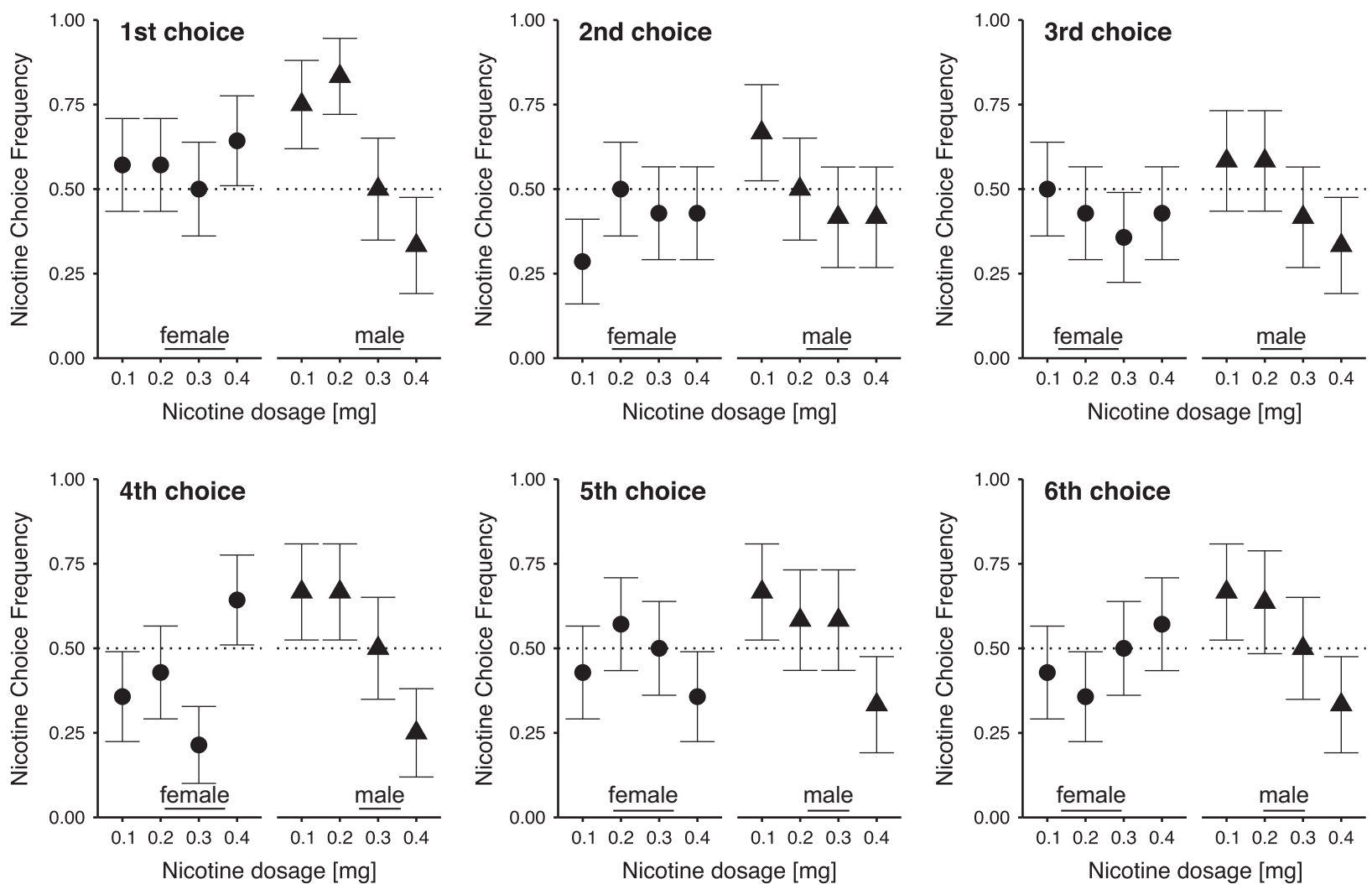

Figure 2 Intravenous nicotine self-administration frequency for each forced-choice trial. The mean ( \pm SEM) frequency for choosing nicotine among male $(n=12)$ and female $(n=14)$ subjects is shown. The numbering indicates the forced-choice trial, I-6.

dose over saline, and 10 out of 12 males (83\%) chose the $0.2 \mathrm{mg}$ nicotine dose over saline. The responses at each forced-choice option for males and females are shown in Figure 2.

\section{The Positive and Negative Subjective Ratings of Low Doses of IV Nicotine}

All nicotine doses $(0.1,0.2,0.3$, and $0.4 \mathrm{mg})$ were rated as more pleasurable than saline (Figures 3 and 4 ). The betweendose increases in ratings of pleasurable effects were subtle and not supported statistically. There were interactions between nicotine dose and drug (nicotine vs placebo) for ratings of stimulatory effects (ANOVA Type Statistic $\left.(\mathrm{ATS})_{2.8}=6.97, P=0.0002\right)$ and aversive effects $\left(\mathrm{ATS}_{2.47}=\right.$ 3.92, $P=0.01)$. These interactions indicated that the ratings of stimulatory effects were higher relative to saline at doses of 0.3 and $0.4 \mathrm{mg}$, but not at doses of 0.1 and $0.2 \mathrm{mg}$, and that aversive effects were significantly higher in response to nicotine relative to saline at $0.3 \mathrm{mg}$, but not at the other nicotine doses. Figure 4 shows the average saline-normalized subjective ratings for stimulatory, pleasurable, and aversive effects following nicotine treatment for male and female subjects grouped separately. Supplementary Figure S1 shows the subjective ratings for stimulatory, pleasurable, and aversive effects in response to saline and nicotine at all time points for male and female subjects grouped separately. There were no significant effects involving sex. In the total sample, stimulatory and pleasurable effects were 20-98\% greater than saline at all nicotine doses. The average aversive rating following 0.1 and $0.2 \mathrm{mg}$ nicotine doses were 11.8 and $12.0 \%$ less than the aversive ratings following saline treatment, whereas the average aversive ratings following 0.3 and $0.4 \mathrm{mg}$ nicotine treatment were 43.7 and $23.2 \%$ greater than the aversive ratings following saline treatment.

\section{The Acute Cardiovascular Effects of Low Doses of IV Nicotine}

HR showed an interaction between nicotine dose and drug $\left(\mathrm{F}_{(3,95.7)}=9.24, P<0.0001\right)$ such that nicotine doses $\geqslant 0.2 \mathrm{mg}$ increased HR relative to saline $(P<0.0001)$. SBP responded to nicotine dose $\left(\mathrm{F}_{(3,68.8)}=3.25, P=0.03\right)$ and drug $\left(\mathrm{F}_{(1,95)}=\right.$ $13.95, P=0.0003)$. Across nicotine doses the estimated mean $(M(\mathrm{SE}))$ SBP was higher during nicotine conditions compared with placebo (116.3 (1.6) vs 114.5 (1.6), $P=0.0003$ ), but the nicotine dose by drug effect on SBP was not significant $\left(\mathrm{F}_{(3,95)}=2.22, P=0.09\right)$. DBP showed interactions between sex and nicotine dose $\left(\mathrm{F}_{(3,69)}=3.53, P=0.02\right)$ such that DBP significantly increased with nicotine doses in males $\left(\mathrm{F}_{(3,69.1)}=5.60, P=0.002\right)$ but not in females $(P=0.15)$. In males, DBP was significantly higher at $0.3 \mathrm{mg}(M(\mathrm{SE})=73$ (22.7) $)$ and $0.4 \mathrm{mg}(M(\mathrm{SE})=71.8(2.7))$ compared with $0.1 \mathrm{mg}(M(\mathrm{SE})=68.9(2.7))$ and $0.2 \mathrm{mg}(M(\mathrm{SE})=69.5$ (2.7); Figure 5). Supplementary Figure S2 shows the cardiovascular response to saline and nicotine at all time points for male and female subjects grouped separately. There was no discernable influence of sex on the effect of $0.1,0.2,0.3$, or $0.4 \mathrm{mg}$ nicotine $v s$ saline on HR or SBP (sex by drug, $P>0.05$ ). 

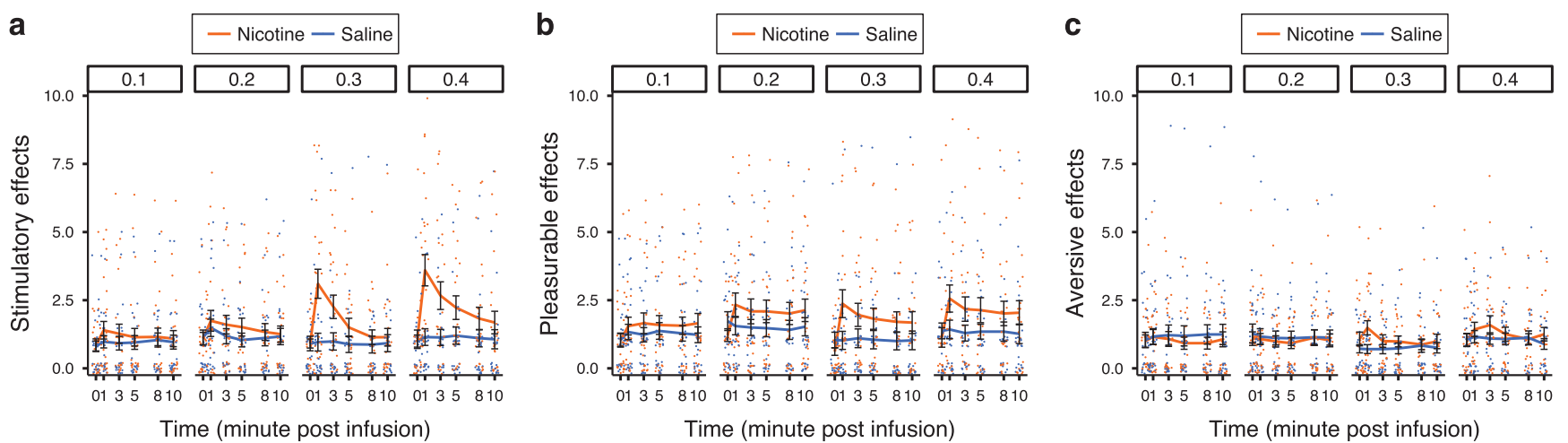

Figure 3 Dose sensitive differences in the subjective ratings of intravenous nicotine. The mean ratings ( \pm SEM) for (a) stimulatory, (b) pleasurable, and (c) aversive subjective drug effects in response to intravenous infusions of nicotine or saline are shown. Responses are grouped horizontally by escalating nicotine dose $(0.1,0.2,0.3$, and $0.4 \mathrm{mg})$.
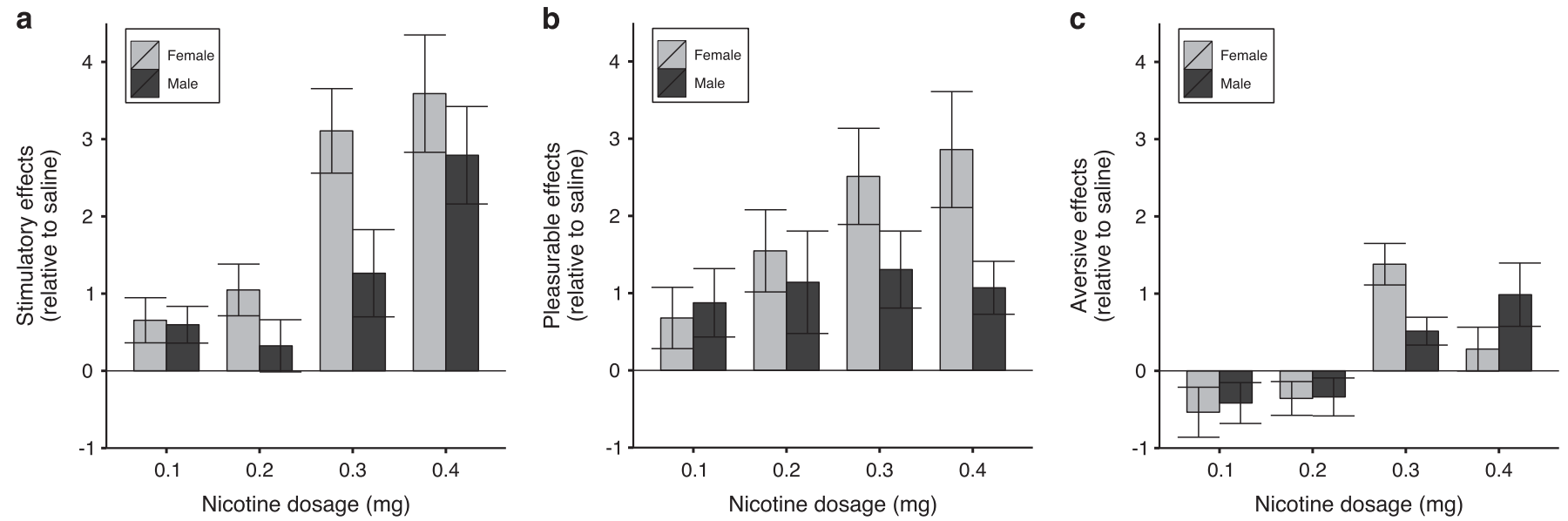

Figure 4 The subjective rating of intravenous nicotine among male and female smokers. Shown is the mean value ( \pm SEM) for 6 post-infusion ratings of (a) stimulatory, (b) pleasurable, and (c) aversive subjective drug effects for male $(n=12)$ and female $(n=\mid 4)$ subjects. The subjective ratings for nicotine are relative to the ratings for saline, using the Drug Effects Questionnaire with a scale of 0-10.

\section{DISCUSSION}

The purpose of this study was to characterize the doseresponse function for IV NSA in male and female smokers. Precise doses of nicotine were administered to smokers by IV infusion at concentrations that an individual might experience while puffing on a typical tobacco cigarette $(0.1,0.2,0.3$, or $0.4 \mathrm{mg}$ ). Among males, low doses of IV nicotine were preferentially chosen over high doses of nicotine. In contrast, among females no choice preference was observed. The IV nicotine doses also induced subjective ratings of positive and negative drug effects that differed from saline. Notably, all doses tested, including the lowest tested dose $(0.1 \mathrm{mg})$, were rated as more pleasurable than saline, indicating abuse potential for all tested doses. The dose-dependent sex differences in reinforcement behavior and the dosedependent changes in positive and negative subjective ratings of drug effects are relevant to dependence vulnerability. Sex differences in the effects of nicotine within this dose range may be particularly relevant for understanding individual differences in smoking behavior and in the response to smoking cessation treatments (Battig et al, 1982; Eissenberg et al, 1999; Etter et al, 2000; Hofer et al, 1991; Perkins and Scott, 2008; Zeman et al, 2002).

The IV nicotine doses that had the strongest reinforcing effects among male subjects are approximately equal to the nicotine quantity delivered by a single cigarette puff. Tobacco smokers self-administer 1.0-2.4 mg of nicotine per cigarette via 12-13 puffs that each contain $0.08-0.2 \mathrm{mg}$ of nicotine (Benowitz and Jacob, 1984; Benowitz et al, 2006; Djordjevic et al, 2000). Among males, IV nicotine at 0.1 and $0.2 \mathrm{mg}$, the equivalent nicotine dose of $\sim 1$ cigarette puff, was self-administered $>0.4 \mathrm{mg}$, the equivalent of $\sim 2-4$ cigarette puffs. The nicotine doses that had the strongest reinforcing effects among males could be a benchmark value for future studies that evaluate the addictive potential of nicotine-containing products. Characterizing individual differences (eg, sex or genetic variation) in sensitivity to the reinforcing effects nicotine in this dose range may help identify the mechanisms underlying vulnerability to dependence and improve treatment responses.

Among females, we observed no choice preference between nicotine doses. As reviewed by Perkins $(1995,1996)$, some prior work has suggested that females may be more sensitive than males to non-nicotine-associated cues and less sensitive than males to the reinforcing effects of nicotine. For example, 

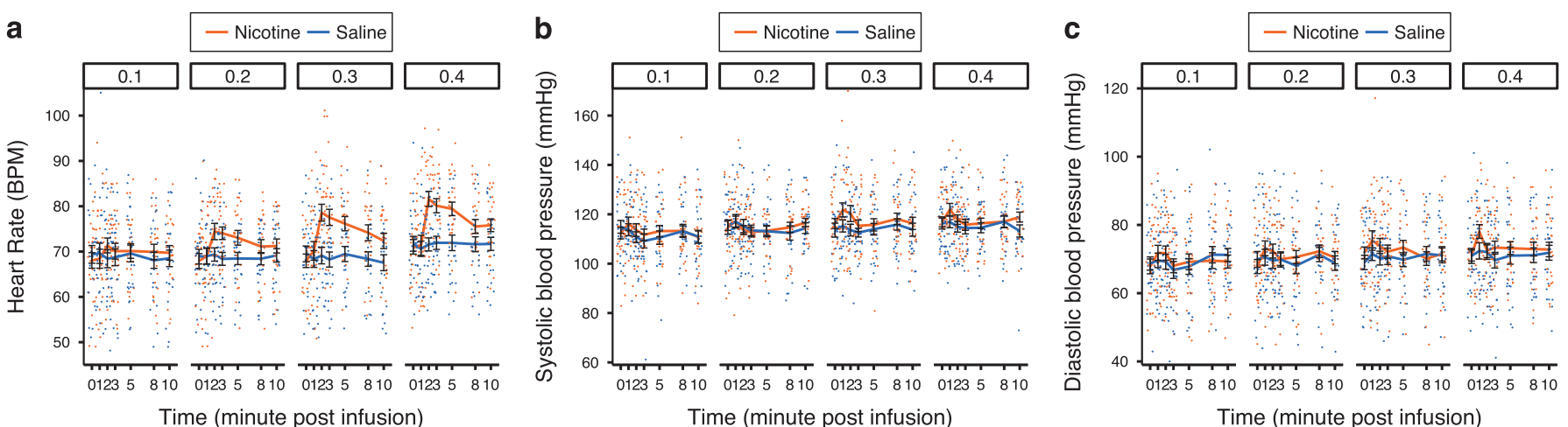

Figure 5 The acute cardiovascular effects of intravenous (IV) nicotine at low doses. The mean ( \pm SEM; a) heart rate, (b) systolic blood pressure, and (c) diastolic blood pressure in response to IV infusions of nicotine or saline are shown. Responses are grouped horizontally by escalating nicotine dose (0.1, $0.2,0.3$, and 0.4 mg).

in a sample of abstinent smokers attempting to quit, Perkins et al (1996) found that males were more likely to administer a nasal spray that contained $0.1 \mathrm{mg}$ nicotine per puff than a placebo spray that contained no nicotine, whereas female subjects were not. A prior study by Grebenstein et al (2013) showed that male rats had greater compensatory increases in nicotine intake following nicotine dose reduction compared with female rats. Our study of male and female smokers showed that males increased the intake frequency as the available nicotine dose was reduced, whereas females did not. There were no significant differences in mean weight or BMI between the male and female subjects; however, body weightadjusted doses might have been required to account for the differences in variability within sexes (females had greater variation in weight). Using body weight, adjusted doses might be a more sensitive approach to determine threshold effects and sex differences. Combined, these studies suggest that male and female smokers may react differently to changes in nicotine doses available for self-administration.

In our study, the response to nicotine was generally equivalent between males and females on cardiovascular measures and on subjective measures. Modest sex differences were observed for the DBP response, with males being more sensitive to the effects of nicotine compared with females. The enhanced subjective ratings of drug effects for females compared with males (Figure 4) at higher nicotine doses were somewhat consistent across outcomes, but not significant (dose by sex $P>0.05$ ). DeVito et al, (2014) found that menstrual cycle phase-specific sex hormone levels were associated with differences in the subject ratings of and physiological response to $0.5-1.0 \mathrm{mg}$ (per $70 \mathrm{~kg}$ body weight) doses of IV nicotine among females. Because sex hormones such as progesterone, which have potent suppressive effects on drug reinforcement in humans and animal models, were not assessed in our study, variation in progesterone levels among females could have confounded our ability to detect differences in the reinforcing effect of different nicotine doses among females. In future studies, it will be important to consider the potential role of sex hormones or menstrual cycle phase.

The effect of nicotine dose on ratings of aversive effects was noteworthy given recent work linking the risk of nicotine dependence to neurobiological pathways that regulate aversive stimuli (Fowler et al, 2011; Frahm et al, 2011; Jackson et al, 2010; Jensen et al, 2015a; Kuryatov et al, 2011; Morel et al, 2014). The interactive effect of dose and drug on aversive ratings was driven in part by aversive ratings at $0.3 \mathrm{mg}$ that were significantly greater than aversive ratings at saline (Figures 3 and 4). The difference between active and saline was not significant at the other dose conditions. In contrast to the aversive effects of nicotine, the ratings of pleasurable effects were greater than saline at all doses with no discernable between-dose differences. The response profiles for aversive $v s$ pleasurable drug effects may relate to the differences in dose preference observed among males. Among males, nicotine doses $<0.3 \mathrm{mg}$ had greater reinforcing effects compared with doses $>0.3 \mathrm{mg}$. Given the sample size, there may have been inadequate statistical power to clearly delineate the boundaries for the positive and negative subjective effects of nicotine, and determine their relation to self-administration behavior. However, it is important to note that prior work indicates that subjective effects may not be required for self-administration of some drugs, eg, opioids (Lamb et al, 1991). Further research on the threshold dose for negative and positive subjective effects of nicotine and reinforcement as measured by choice preference is warranted given the potential links to dependence vulnerability and transition to heavy smoking.

In summary, we have used an IV NSA procedure to characterize the dose-response curve across a variety of subjective and objective measures for nicotine at concentrations that an individual might experience while puffing on a cigarette $(0.1-0.4 \mathrm{mg})$. Nicotine in this dose range induced dose-dependent changes in choice preference behavior that differed by sex, as well as subjective drug effects that are important for evaluating dependence liability. These findings are consistent with previous studies and suggest that male and female smokers may have different dose-response functions for nicotine reinforcement.

\section{FUNDING AND DISCLOSURE}

This work was funded by a US Department of Veterans Affairs Career Development Award to Dr. Jensen and the New England Mental Illness Research Education Clinical, Center (MIRECC). Statistical analyses were supported by the administrative core of the Yale TCORS, which is funded by a grant (P50DA036151) from the National Institutes of Health (NIH) and the Food and Drug Administration (FDA) Center for Tobacco Products (CTP). Dr. DeVito is a Yale TCORS trainee and receives partial salary support from the Yale TCORS. Dr. Sofuoglu has served as an expert witness on behalf of Pfizer in lawsuits related to varenicline. All other authors declare no conflict of interest. 


\section{DISCLAIMER}

The content is solely the responsibility of the authors and does not necessarily represent the official views of the NIH, FDA or US Department of Veterans Affairs.

\section{REFERENCES}

American Psychological Association (1994). Diagnostic and Statistical Manual of Mental Disorders, 4th edn. American Psychiatric Association: Washington, DC, USA.

Battig K, Buzzi R, Nil R (1982). Smoke yield of cigarettes and puffing behavior in men and women. Psychopharmacology (Berl) 76: 139-148.

Benowitz NL, Henningfield JE (1994). Establishing a nicotine threshold for addiction. The implications for tobacco regulation. $N$ Engl J Med 331: 123-125.

Benowitz NL, Jacob P (1984). Daily intake of nicotine during cigarette-smoking. Clin Pharmacol Ther 35: 499-504.

Benowitz NL, Jacob P 3rd (1990). Intravenous nicotine replacement suppresses nicotine intake from cigarette smoking. J Pharmacol Exp Ther 254: 1000-1005.

Benowitz NL, Jacob P, Herrera B (2006). Nicotine intake and dose response when smoking reduced-nicotine content cigarettes. Clin Pharmacol Ther 80: 703-714.

Brunner E, Domhof S, Langer F (2002). Nonparametric analysis of longitudinal data in factorial designs. Wiley: New York, USA.

Corrigall WA, Coen KM, Adamson KL, Chow BL, Zhang J (2000). Response of nicotine self-administration in the rat to manipulations of mu-opioid and gamma-aminobutyric acid receptors in the ventral tegmental area. Psychopharmacology (Berl) 149: 107-114.

DeVito EE, Herman AI, Waters AJ, Valentine GW, Sofuoglu M (2014). Subjective, physiological, and cognitive responses to intravenous nicotine: effects of sex and menstrual cycle phase. Neuropsychopharmacology 39: 1431-1440.

Djordjevic MV, Stellman SD, Zang E (2000). Doses of nicotine and lung carcinogens delivered to cigarette smokers. J Natl Cancer Inst 92: 106-111.

Donny EC, Caggiula AR, Rowell PP, Gharib MA, Maldovan V, Booth $S$ et al (2000). Nicotine self-administration in rats: estrous cycle effects, sex differences and nicotinic receptor binding. Psychopharmacology (Berl) 151: 392-405.

Eissenberg T, Adams C, Riggins EC 3rd, Likness M (1999). Smokers' sex and the effects of tobacco cigarettes: subject-rated and physiological measures. Nicotine Tob Res 1: 317-324.

Etter JF, Vu Duc T, Perneger TV (2000). Saliva cotinine levels in smokers and nonsmokers. Am J Epidemiol 151: 251-258.

Fattore L, Cossu G, Martellotta MC, Fratta W (2002). Baclofen antagonizes intravenous self-administration of nicotine in mice and rats. Alcohol Alcohol 37: 495-498.

Fowler CD, Lu Q, Johnson PM, Marks MJ, Kenny PJ (2011). Habenular alpha5 nicotinic receptor subunit signalling controls nicotine intake. Nature 471: 597-601.

Frahm S, Slimak MA, Ferrarese L, Santos-Torres J, Antolin-Fontes B, Auer $S$ et al (2011). Aversion to nicotine is regulated by the balanced activity of beta 4 and alpha 5 nicotinic receptor subunits in the medial habenula. Neuron 70: 522-535.

Grebenstein P, Burroughs D, Zhang Y, LeSage MG (2013). Sex differences in nicotine self-administration in rats during progressive unit dose reduction: implications for nicotine regulation policy. Pharmacol Biochem Behav 114-115: 70-81.

Harvey DM, Yasar S, Heishman SJ, Panlilio LV, Henningfield JE, Goldberg SR (2004). Nicotine serves as an effective reinforcer of intravenous drug-taking behavior in human cigarette smokers. Psychopharmacology (Berl) 175: 134-142.
Henningfield JE, Goldberg SR (1983a). Control of behavior by intravenous nicotine injections in human-subjects. Pharmacol Biochem Behav 19: 1021-1026.

Henningfield JE, Miyasato K, Jasinski DR (1983b). Cigarette smokers self-administer intravenous nicotine. Pharmacol Biochem Behav 19: 887-890.

Hofer I, Nil R, Battig K (1991). Nicotine yield as determinant of smoke exposure indicators and puffing behavior. Pharmacol Biochem Behav 40: 139-149.

Jackson KJ, Marks MJ, Vann RE, Chen X, Gamage TF, Warner JA et al (2010). Role of alpha5 nicotinic acetylcholine receptors in pharmacological and behavioral effects of nicotine in mice. J Pharmacol Exp Ther 334: 137-146.

Jensen KP, DeVito EE, Herman AI, Valentine GW, Gelernter J, Sofuoglu M (2015a). A CHRNA5 smoking risk variant decreases the aversive effects of nicotine in humans. Neuropsychopharmacology 40: 2813-2821.

Jensen KP, Herman AI, Morean ME, Kranzler HR, Gelernter J, Sofuoglu M (2015b). FKBP5 variation is associated with the acute and chronic effects of nicotine. Pharmacogenomics J 15: 340-346.

Kuryatov A, Berrettini W, Lindstrom J (2011). Acetylcholine receptor (AChR) alpha5 subunit variant associated with risk for nicotine dependence and lung cancer reduces (alpha4beta2)(2) alpha5 AChR function. Mol Pharmacol 79: 119-125.

Lamb RJ, Preston KL, Schindler CW, Meisch RA, Davis F, Katz JL et al (1991). The reinforcing and subjective effects of morphine in post-addicts: a dose-response study. J Pharmacol Exp Ther 259: 1165-1173.

Le Foll B, Wertheim C, Goldberg SR (2007). High Reinforcing efficacy of nicotine in non-human primates. PLoS One 2: e230.

Morean ME, de Wit H, King AC, Sofuoglu M, Rueger SY, O'Malley SS (2013). The drug effects questionnaire: psychometric support across three drug types. Psychopharmacology (Berl) 227: 177-192.

Morel C, Fattore L, Pons S, Hay YA, Marti F, Lambolez B et al (2014). Nicotine consumption is regulated by a human polymorphism in dopamine neurons. Mol Psychiatry 19: 930-936.

Perkins KA (1995). Individual variability in responses to nicotine. Behav Genet 25: 119-132.

Perkins KA (1996). Sex differences in nicotine versus nonnicotine reinforcement as determinants of tobacco smoking. Exp Clin Psychopharmacol 4: 166-177.

Perkins KA, Grobe JE, DAmico D, Fonte C, Wilson AS, Stiller RL (1996). Low-dose nicotine nasal spray use and effects during initial smoking cessation. Exp Clin Psychopharmacol 4: 157-165.

Perkins KA, Scott J (2008). Sex differences in long-term smoking cessation rates due to nicotine patch. Nicotine Tob Res 10: $1245-1251$.

Pogun S, Yararbas G (2009). Sex differences in nicotine action. Handb Exp Pharmacol 261-291.

Rose JE, Corrigall WA (1997). Nicotine self-administration in animals and humans: similarities and differences. Psychopharmacology (Berl) 130: 28-40.

Sofuoglu M, Yoo S, Hill KP, Mooney M (2008). Self-administration of intravenous nicotine in male and female cigarette smokers. Neuropsychopharmacology 33: 715-720.

Soria R, Stapleton JM, Gilson SF, Sampson-Cone A, Henningfield JE, London ED (1996). Subjective and cardiovascular effects of intravenous nicotine in smokers and non-smokers. Psychopharmacology (Berl) 128: 221-226.

Zeger SL, Liang KY, Albert PS (1988). Models for longitudinal data: a generalized estimating equation approach. Biometrics 44: 1049-1060.

Zeman MV, Hiraki L, Sellers EM (2002). Gender differences in tobacco smoking: Higher relative exposure to smoke than nicotine in women. J Womens Health Gend-Based Med 11: 147-153. 